Two other types of solids in addition to those already mentioned are susceptible of mathematical treatment, namely, the solids derived by the rotation of a circle round an axis not passing through its centre. When the axis does not cut the circle a ring with a circular section is produced, such as an ordinary finger ring, which is open at the middle. When the axis cuts the circle, a solid, which Lindemann calls a "Wulst" or roll, and resembles in form an orange or an apple--is generated. A particle having the first of these shapes, when rendered luminous, would, according to the mathematical theory, give rise to lines having wave-lengths dependent on four numbers, to each of which a series of values can be given. The kind of spectrum which results can best be explained by imagining the spectrum due to a luminous particle of the elongated ellipsoidal type to be displaced several times in succession, the relative position of the lines being slightly modified in each shift. Such a spectrum has already been found to characterise oxygen and helium; the oxygen spectrum, indeed, according to Runge and Paschen, appears as if derived from that of an alkali metal by a series of successive displacements. An atom of the second type, with a shape similar to that of an apple, when rendered luminous, would, according to the calculations, give rise to a spectrum such as would be produced by successive displacements of the lines due to a flattened ellipsoid. The spectra of sulphur and selenium seem, indeed, to be of this type, being derived from a spectrum like that of oxygen by substituting single strong lines for certain groups of lines. The atom of oxygen thus appears to have the form of an open ring, the atom of sulphur or selenium that of a "Wulst."

Certain interesting consequences concerning the chemical properties of the elements follow from a consideration of their shape, and have been developed by Prof. Lindemann. That the ring-shaped oxygen atom, for example, is a dyad with regard to hydrogen at once follows from the plate-like shape of the hydrogen atoms, two of these being necessary to close the two apertures of the ring. A distinction, moreover, such as is actually found to exist, is introduced at the outset between valency with regard to hydrogen and valency with regard to oxygen. Apart from speculations of this kind, Prof, von Lindemann's work has great significance at the present moment, in that it demonstrates the possibility to derive those physical constants which most clearly define and characterise the individual elements from the conception of a single kind of matter merely by introducing the idea of shape. It is, of course, possible that the atoms do not possess strictly, but only approximately, the simple shapes which can be treated mathematically. If this were so, slight changes would be introduced into the transcendental equations, and the deduced values, for example those in the table given, can be considered only as a first approximation; but the approximation is sufficiently close to justify the belief that the general type of the transcendental equations is correct.

W. A. D.

\section{THE TIME OF FRANCE.}

A NOTE from the Paris correspondent of a daily journal stating that the proposal to adopt Greenwich time in France is again being brought forward, a desirable reform which would bring our nearest neighbour into harmony. in this respect with almost the whole of Europe, may be considered a sufficient reason for giving some facts on the subject under discussion.

Without going back to the earliest proposals for establishing a time-system which should be common to the whole world, an early stage in the movement was the calling of a conference by the Government of the United States to be held at Washington in October, I884. At this meeting, which was attended by representatives of twenty-five nations, but who, it must be remembered, had no power to bind their Governments to any plan of action, it was resolved that "the Conference proposes to the Governments here represented, the adoption of the meridian passing through the centre of the transit instrument at the Observatory of Greenwich as the initial meridian for longitude." This resolution was voted for by representatives of twenty-two countries, one representative took the opposite view, and two countries, of whom France was one, abstained from voting.

Following on this, a resolution was passed at the meeting adopting the principle of a universal day which should begin at mean midnight of the initial meridian, a scheme containing the germ of the present hourly zone system. But a more practical step had already been taken by the managers of the American railways, who, in November, I883, had adopted the now well-known system in which the American continent is divided into five zones, the time used in each of which is respectively $4,5,6,7$, and 8 hours slow on Greenwich. It says much for the breadth of view of the American railway managers, who thus rose above all consideration of national feeling and selected a zero which was likely to suit the convenience of the greatest number, and set an example which must have done much to forward the scheme.

Since 1884 there has been no open international intercourse on the subject, but gradually the zone time system has made its way. In I892 Belgium and Holland began to use Greenwich time; in 1893 mid-European time, one hour fast on Greenwich, was made the legal standard time in Germany and Italy; in the next year the same time was adopted in Switzerland and Denmark, and in 1895 in Norway, Mid-European time had already been in use in Sweden many years, and on the Austrian, Hungarian, Servian, and Macedonian railways since I89I, but, strangely enough, Vienna, the home of Dr. Schram, who was one of the leaders of the movement for the unification of time, has not adopted any legal standard time. The meridian of Pulkowa happens to be 2 hours I minute east of Greenwich, and since the time of this meridian is used for telegraph work and on the railways of Russia, it may be considered that this country uses east European time, two hours fast on Greenwich, which is also used for some purposes in Turkey. Since Greenwich time was made the legal time of Spain in Igoo, it will be seen that almost the whole of Europe has fallen in line. France has not held aloof for want of consideration of its merits. In 1896 the proposition that the Greenwich meridian should be adopted in France was brought by $M$. Deville before the Chamber of Deputies, and being voted on was accepted by that body, but the matter went no further, the reason for which may be inferred from the proceedings at the meeting of the Astronomical Society of France held on December 2, 1896 . At that meeting several of the leading scientific men of France were present, and among them M. Bouquet de la Grye, who, after expressing his astonishment that scientific men had not been consulted before such a proposition was made, proceeded to raise objections. It was true, said he, that the meridian of Greenwich had been chosen as initial because of the greatness of England's seapower; but, he asked, how long would this continue? England's supremacy in this respect might pass away just as had that of other nations, and what then? 
Also he urged that Greenwich was too far north as a situation for an observatory to fix the standard meridian, and again, that the position of Greenwich with respect to the observatories of the Continent was not then accurately known. Another speaker, whose opinions are worthy of respect, remarked that France was not alone among the countries in not joining the movement, for Spain used its own time, and also-it is to be feared that here he made a strong point-Ireland, even, still used Dublin time. It was affirmed that the motives which influenced the French authorities in this matter were purely of a scientific nature, but it may be noted that since that meeting the proposition has been brought forward in other words, namely, that the legal standard time of France shall be 9 minutes $2 \mathrm{I}$ seconds slow on the time of the meridian of Paris, which is not unlike the former proposal, except verbally, and it might be thought that the alteration was made so as not to hurt some susceptibilities. However, the change has not yet been made. Some of the objections above quoted have vanished, for England's naval power has as yet suffered no reverse, Spain has adopted Greenwich time, and the difference of longitude between Greenwich and Paris has been again determined, with a result which may be accepted as final. Ireland still continues to use Dublin time, it is true, but even this ought not to outweigh any advantages that might accrue from the change.

H. P. H

\section{THE COLOMBIAN EARTHQUAKE.}

$\mathrm{N}^{\mathrm{N}}$ January $3^{\mathrm{I}}$, we learn from vague messages, an earthquake of unusual severity occurred in the north-west part of South America. The report stated that towns and villages had been destroyed, and islands had sunk. The disappearance of the latter was, however, so gradual that the inhabitants had been able to escape in boats. Later information told us about the interruption of cables, and reported that in consequence of huge sea waves a long line of coast between Buenaventura and Tumaco and the western coast of the Republic of Colombia had been devastated for many leagues. A great catastrophe had evidently occurred, but until sixteen days later the East knew but little as to what had actually taken place. The seismographs in Britain and in other countries have, however, told a story. Later we shall have another story from our Consuls and our newspapers.

In the Isle of Wight the record of some great earth adjustment commenced, as reckoned in our time, at 3 h. $47 \mathrm{~m}$. p.m. Its maximum occurred some thirty-five minutes later. From these facts the distance at which the mass displacement had originated was known, and by a simple computation, based upon this distance, the time at the origin would be in Colombian time approximately roh. 9m. a.m. Better that the disturbance occurred in the morning, when heavings of the ground could be felt and high waves suggesting refuge on higher ground could be seen, than it should have occurred when the inhabitants of towns and villages on a seaboard were at rest. Two hours later the effects of the initial impulses had reached their antipodes, and in the interval between these times every inhabitant of the world had been moved for at least three or four hours on a true ground swell. All the instruments in the world designed to record teleseismic motion had written records, the bubble in every spirit level had been fitfully oscillating to and fro, many magnetic needles had been caused to swing, balances had oscillated, pendulums had been accelerated or retarded-the whole world, not only on its surface, but in its depths had been shaken. The internal constitution of our planet had been disturbed, that which is hypogenic may have produced its effect upon that which was epigenic, there was a flicker in the life-history of the earth.

At this moment it is not for us to enter into the whys and wherefores of the Colombian disaster. It suddenly came upon the scene in the last day of January, but it is not yet ended. Shocks continued for the next five days, and although we are without information, they will doubtless continue for many days to come. Among other things beyond these immediate effects on life and property, we learn that volcanic stress was relieved at Cumbal. Further, we learn that on February 16 severe shocks were experienced in the Antilles. At r.40 p.m. on that date walls were cracked in St. Vincent; similar reports come from Fort de France, and cables have been broken.

History repeats itself, and this is particularly illustrated in the seismic and volcanic history of the Central American and West Indian subterranean activities. A convulsion in the one is followed by a reaction in the other. The last illustration, which is only one of a long series, occurred in 1902 , when terrific readjustments of strata in Guatemala were quickly followed by the holocaust of St. Pierre. The Colombian disaster of January $3 \mathrm{I}$, to which we particularly refer, is the last of a series with which seismologists are familiar. We do not know for certain, but its origin was probably suboceanic off the mouth of the Esmeralda River. We can at least say that on the line we have indicated there is a rapidly descending suboceanic gully, and that cables crossing this line have frequently been interrupted. To this we may add that here we have a district where submerged land slopes are unusually steep, and where those who lay deep-sea cables tell us that soundings have from time to time been greatly changed. Out of fifteen cable interruptions which have taken place in the district under consideration, nine of them occurred at the time when seismographs or instruments which would record teleseismic effects were set in motion in Europe. Interruptions to cables come in many ways, but from time to time we know that they have come about by sudden changes in the form of ocean floors, and off the mouth of the Esmeralda River we know that this has often happened.

\section{NOTES.}

THE appointment of officers for the seventy-sixth meeting of the British Association, which is to be held at York, has now been completed. The meeting will open on Wednesday, August I-when the president, Dr. E. Ray Lankester, F.R.S., will deliver the presidential addressand be concluded on August 8. The following are the names of the presidents of the various sections :-A (mathematical and physical science), Principal E. H. Griffiths, F.R.S.; B (chemistry), Prof. Wyndham Dunstan, F.R.S.; C (geology), Mr. G. W. Lamplugh, F.R.S.; D (zoology), Mr. J. J. Lister, F.R.S.; E (geography), Sir G. TaubmanGoldı, K.C.M.G., F.R.S.; F (economic science and statistics), Sir George S. Gibb; G (engineering), Prof. J. A. Ewing, F.R.S.; H (anthropology), Mr. E. Sidney Hartland; I (physiology), Prof. Francis Gotch, F.R.S.; K (botany), Prof. F. W. Oliver, F.R.S.; L (educational science), Prof. M. E. Sadler. Subscriptions to the amount of more than $700 l$. have been promised to the fund started for the purpose of founding a medal to commemorate the visit of the association to South 